Revista Iberoamericana, Vol. LXXIX, Núm. 243, Abril-Junio 2013, 337-347

\title{
SABER DE AUSENCIA
}

\author{
POR \\ Gustavo Pérez Firmat \\ Columbia University
}

\author{
O absence, you are here so often \\ they will have to change your name. \\ Jorge Guitart, The Empress of Frozen Custard
}

Le debemos a Rafael Rojas el haber recordado la frase de Mercedes García Tudurí que encabeza mi ensayo. De raíz religiosa, el saber de ausencia nombra la seguridad del creyente ante la existencia de Dios. Es, por lo tanto, un saber que se desliza hacia la fe: confianza tanto como conocimiento. Aquí me interesa, sin embargo, reflexionar sobre una variante laica de este saber, la que tiene por sujeto no al creyente sino al desterrado. Como señala Rojas el poemario donde aparece la frase, Ausencia (1968), debe leerse no sólo como un acto de fe, sino como una reflexión a lo divino sobre el exilio, algo así como una primera versión de otro de los libros de García Tudurí, Tiempo de exilio (1983), en el cual la poeta, al llamarse "andariega de Dios", funde lo político con lo sagrado, el destierro con la criaturalidad (28-29).

En el contexto del exilio, la frase tiene dos acepciones: por una parte, designa la ganancia en sabiduría que la ausencia hace posible; por otra, el conocimiento de la ausencia en sí, de sus causas, vivencias y secuelas afectivas. Siguiendo al historiador norteamericano Dominick LaCapra, conviene distinguir, además, entre pérdida y ausencia (44). El que padece la ausencia no es un perdedor, aunque haya perdido. Al perdedor algo le ha sucedido. Su pérdida es transitiva, tiene un complemento: alguna posesión, un ser querido, su país. La ausencia carece de transitividad. Al expresarse como verbo, deviene una acción reflexiva que recae sobre el sujeto: ausente es quien se ausenta. Y aunque un perdedor también puede perderse, el que se ausenta no se pierde. A veces sucede todo lo contrario y en la ausencia se halla a sí mismo. En un sentido estricto, la ausencia es la pérdida de lo que nunca se tuvo, una pérdida en sí perdida. De ahí que su tesitura afectiva, como señala LaCapra, sea la melancolía en vez del luto (48).

Sucede, sin embargo, que una pérdida de mucha duración, que se hace crónica e irreversible, llega a experimentarse como ausencia. Para el perdedor a largo plazo, el objeto de la pérdida se desvanece, y lo que ya no se tiene se confunde con lo que nunca 
se tuvo. Cuando esto sucede, el luto por la pérdida se desliza hacia la melancolía por lo ausente - una melancolía sin fin, ya que no hay manera de restituir lo que nunca fue-. Así ocurre, por ejemplo, en la obra de escritores cuyo destierro se prolonga por varias décadas, en particular si abandonaron su país natal muy jóvenes. Esta es la situación de los integrantes de la "primera generación cubanoamericana" (Rojas 26) o "la generación 1.5" (Pérez Firmat 18): Roberto Fernández, Cristina García, Carolina Hospital, Dionisio Martínez, Pablo Medina, Elías Miguel Muñoz, Achy Obejas, Virgil Suárez (entre otros). El saber de ausencia le imparte a la patria largamente perdida un carácter fantasmático e irreal. Más que un referente histórico es una figura de la imaginación. Como en la novela de Cristina García, Dreaming in Cuban (1992), Cuba no se recuerda, se sueña.

Dos poetas que ilustran a plenitud las consecuencias estéticas de esta coyuntura generacional son Orlando González Esteva (1952) y Ricardo Pau-Llosa (1954). Aunque sus carreras han seguido derroteros muy distintos -González Esteva ha escrito toda su obra en español y Pau-Llosa casi toda en inglés; González Esteva publica sus libros en México y España; Pau-Llosa en Estados Unidos- sus poesías muestran afinidades que trascienden las diferencias idiomáticas y de temperamento. Sabios de ausencia, ambos han hecho del exilio a largo plazo la condición de posibilidad de su escritura, que funde la nostalgia del exiliado con el asombro del que ve algo por primera vez.

Oriundo de Palma Soriano, en la antigua provincia de Oriente, González Esteva arribó a Estados Unidos en 1965. Desde entonces reside en Miami. Ha publicado una docena de libros en prosa y verso, entre ellos: Mañas de la poesía (1981), El pájaro tras la flecha (1988), Escrito para borrar (1997), Cuerpos en bandeja (1998), Mi vida con los delfines (1998), Elogio del garabato (1994), La noche y los suyos (2003), Casa de todos (2005), ¿Qué edad cumple la luz esta mañana? (2008). La decisión de González Esteva de vivir y escribir en español ha dejado un saldo de exclusiones y recompensas. Tanto las unas como las otras se hacen evidentes en esta declaración: "El que busque en mis versos la presencia de mi larga vida en Estados Unidos, la huella de la literatura anglosajona, no la encontrará, a pesar de que me eduqué en ese país y vivo en él. Encontrará sólo a Cuba" (Asiaín 55). La postura de González Esteva es análoga a la de otro poeta de la diáspora cubana, José Kozer, en cuya poesía también aparecen pocas huellas de su larga estadía en Estados Unidos. ${ }^{1}$ A diferencia de Kozer, sin embargo, cuyos poemas se distinguen por acoger los más diversos registros y variedades del castellano, González Esteva rehúye del esperantismo en favor de un nativismo de segundo orden. La suya es una lengua que a la vez que identifica a su autor como escritor cubano $-E l$ pájaro tras la flecha incluye un glosario de localismos, como las novelas criollistas del último siglo- revela la lejanía (en años y en leguas) de su tierra natal.

Sobre Kozer, véase Pérez Firmat (170-187).

Revista Iberoamericana, Vol. LXXIX, Núm. 243,
ISSN 0034-9631 (Impreso) 
Buen ejemplo de ello es un libro de haikus, La noche y los suyos (2005), donde se refiere a sus poemas como "señales de humo" (19), metáfora que representa la comunicación a distancia. Ahora bien, González Esteva siempre ha favorecido géneros y formas menores: el aforismo, la redondilla, la décima, el haiku. En Tallar en nubes (1999), una recopilación de apuntes espigados de los cuadernos de Martí, González Esteva explica que el libro reúne "un puñado de textos germinales, vivos, acabaditos de garrapatear" (xii). La frase podría aplicarse con igual derecho a su propia obra, que consiste en el registro pormenorizado, en verso o prosa, de sensaciones, recuerdos, atisbos, ocurrencias, epifanías. Como señala en Elogio del garabato (1994), escribir es garabateo, garrapateo, y "toda obra de arte, antes de serlo, fue garabato, es decir, atisbo, vacilación, esbozo. Es más, toda obra de arte, por terminada que parezca, sigue siendo garabato" (36). No es sorprendente, por eso, que su mirada se fije en lo efímero o lo nimio: una gota de agua o de tinta, el punto sobre la jota. Devoto de lo mínimo, con una "pasión por la brevedad" (Casa 5), González Esteva hasta le ha dedicado un librito a las hormigas, Fosa común (1996), que abre con esta redondilla:

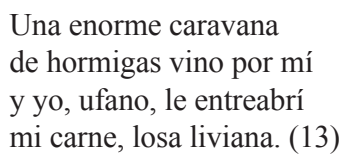

Uno de los haikus de La noche y los suyos se detiene, ya no en las hormigas, sino en sus primos alados, los mosquitos:

Hola, mosquito.

¿Te da miedo la noche?

Zumba un poquito. (32)

Todo es pequeño: el poema, el mosquito y el diminutivo que cuadra la rima-poquito-. Más que un tic, manía o amaneramiento, la práctica del garrapateo u hormigueo ("escribir es hormiguear" [Fosa 25]), refleja la situación de González Esteva como escritor de lengua española en Estados Unidos. Separado de su patria y de gran parte del que debiera ser su público lector, no le queda más remedio que garrapatear, hormiguear, entregarse a redactar apuntes embrionarios. A falta de país, falta de fines. Herido de exilio, él mismo es un ser incompleto: "feto que alucina", "larva que sueña" (Fosa 35). González Esteva no escribe ensayos o poemas extensos. Es, en el más noble sentido, un escritor de ocasión, lo cual queda ya sugerido en el garabato como metáfora de la escritura. En tanto "graffiti en el muro de las lamentaciones" (Elogio 37), el garabato registra impresiones en peligro de desaparición (otro de sus libros: Escrito para borrar).

Revista Iberoamericana, Vol. LXXIX, Núm. 243, Abril-Junio 2013, $337-347$
ISSN 0034-9631 (Impreso) 
Esta sensación de precariedad, de fugacidad, de incompletez, acompaña toda su obra. Como el mosquito, el poeta teme la extinción. En reacción, "zumba un poquito".

Entre las docenas de haikus de González Esteva, pocos se refieren abiertamente a Cuba. Uno de ellos se encuentra en Casa de todos (2005):

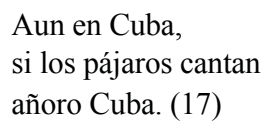

El poema remeda un haiku de Bashō, uno de los maestros del género. En inglés -González Esteva indica que su versión se basa de la traducción al inglés del original japonés- el haiku se traduce de esta manera:

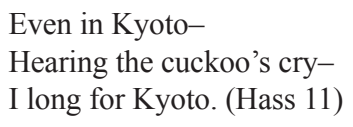

Puesto que en la poesía japonesa el cucú del cucú, el "ave del tiempo", connota temporalidad, la paradoja de añorar a Kyoto estando en Kyoto expresa nostalgia por un tiempo perdido. Como apunta uno de los comentaristas de Basho: "With the cry, today's Kyoto is instantly transformed into the Kyoto of the past" (Ueda 294). En la versión de González Esteva, la sustitución de Cuba por Kyoto parece manifestar el anhelo por la mítica "Cuba de ayer", que es la Cuba de su niñez. También es posible que González Esteva esté plasmando la convicción melancólica de que Cuba, como dijera Jorge Mañach en Historia y estilo (1944), es una patria sin nación. En este caso, el país que no existe -otro "feto que alucina"- es el que no ha cumplido su destino como república.

Pero el que González Esteva no viva (y nunca haya vuelto) a Cuba complica estas lecturas. A diferencia de la de Bashō, la añoranza de González Esteva no es sólo temporal sino geográfica, una nostalgia inspirada no sólo por la Cuba que fue o que nunca ha sido, sino por la patria distante. Por eso reemplaza el nombre de una ciudad-Kyoto-por el de un país -Cuba-. En boca de un exiliado, la paradoja de sentirse ajeno en casa propia produce una afirmación contrafáctica: "en Cuba... añoro". La expresión más profunda de añoranza no yace en extrañar a Cuba estando en Cuba, sino en ubicarse en un país que González Esteva no ha visto en más de cuarenta años.

Escrita sin tilde, la primera palabra del poema, "Aun”, es monosílaba. No obstante, para que el verso alcance las cinco sílabas exigidas por la métrica del haiku, hay que romper el diptongo con un acento prosódico. Es preciso leer "Aun" como si fuera "Aún". De este modo, "aun" ("hasta") se metamorfosea en "aún" ("todavía"). "Aun en Cuba" significa entonces "todavía en Cuba," un cambio que subraya la ilusión de sedentarismo, de nunca haber abandonado el suelo natal. Ese acento invisible pero

Revista Iberoamericana, Vol. LXXIX, Núm. 243, Abril-Junio 2013, $337-347$
ISSN 0034-9631 (Impreso) 
necesario, esa otra pequeñez, dibuja la huella del saber de ausencia, prueba fehaciente de la realidad de lo invisible. Según González Esteva, Cuerpos en bandeja, un ciclo de conferencias sobre la relaciones eróticas del cubano con las frutas, no es otra cosa que un intento de repatriación: "Cuerpos en bandeja no es un ensayo ni una suma de conferencias, géneros demasiado específicos y, por lo regular, adustos, para admitir discurso tan desenfadado. Es lo que fue: un pretexto para retomar y compartir, devota y distraídamente -gozosamente, debería decir- algunas lecturas, y, retomándolas, repatriarme" (¿Qué edad...? 149). Lo mismo podría decirse del haiku. El saber de ausencia se dirime en actos de imaginada presencia.

Otra novedad en la reiteración cubana del haiku japonés es la sustitución del cucú o cuclillo del original con el genérico "pájaros". La sustitución se debe, en primer lugar, a que en Cuba no hay cuclillos y, en segundo, a que en español el cuclillo carece de la capacidad de evocación que tiene en japonés. Pero hay una justificación más, quizás la definitiva. Otro de los haikus de Casa de todos dice:

\section{Toda la noche}

oyeron pasar pájaros...

Tú aún los oyes. (31)

Los dos primeros versos citan la conocida frase del Diario de a bordo de Colón. La frase aparece en la entrada correspondiente al 9 de octubre, tres días antes de arribar a la isla de Guahaní. Para los tripulantes de las carabelas, la presencia de pájaros indicaba que la tierra estaba cerca. Quinientos años después, un poeta exiliado se identifica con Colón y sus marineros, como si el poeta también estuviera a punto de descubrir un mundo nuevo. Mas para González Esteva este mundo nuevo no es terra incognita sino el terruño que lo vio nacer. Al exiliado a largo plazo la patria se le vuelve extraña, una destinación tan fabulosa como las Indias soñadas por Colón. (Saber de ausencia: el canto de pájaros que no existen.)

González Esteva no sólo oye los pájaros; los oye todavía, aún: “Tú aún los oyes.”Ya no hay ambigüedad en el significado del adverbio. Aún aúna. Denota continuidad entre el descubridor de Cuba y el poeta; entre el muchacho que vivió los doce primeros años de su vida en Palma Soriano y el hombre que ha vivido más de cuarenta en Miami; entre la patria ausente y la patria perdida. (Saber de ausencia: el aún del todavía.) No importa el tiempo que pase, el niño sigue siendo el padre del hombre, como dijera Wordsworth. A pesar de haber vivido fuera de Cuba toda su vida adulta, la sensación de inmediatez, la fe en la cercanía de la patria persiste. Y el "tú" que el poema interpela no es sólo el poeta sino todos los que viajan con él, otros exiliados que comparten la misma fe.

El epígrafe de La noche y los suyos repite la pregunta más famosa de la literatura cubana: "Dos patrias tengo yo, Cuba y la noche:/ ¿O son una las dos?” A la interrogante martiana, González Esteva responde afirmativamente en el primer poema del libro:

\footnotetext{
Revista Iberoamericana, Vol. LXXIX, Núm. 243, Abril-Junio 2013, 337-347 


\author{
La noche suma \\ demasiadas ausencias. \\ Es, toda, Cuba. (15)
}

En este haiku el minimalismo se pone al servicio de la hipérbole: la noche suma, es una summa, de "demasiadas" ausencias. Prolongando la hipérbole, el tercer verso equipara la totalidad de la noche con Cuba. El silogismo poético que subyace a esta afirmación reza así: La noche es ausencia; Cuba está ausente; luego, Cuba es la noche: "son una las dos". El peso afectivo del razonamiento cae sobre "toda", que reúne la primera y la última vocal de los vocablos que une: la noche y Cuba. (Si libramos a "toda" de las comas que la rodean, toda Cuba se integra al silogismo.) No es casualidad que el primer verso del haiku que sigue es "La noche pesa". Lastrada de ausencia, la noche de González Esteva, como la de Martí, se resiente del peso, del pesar, de la añoranza. Por eso el libro se titula La noche y los suyos: el poeta pertenece a la noche, porque la noche pertenece a Cuba. Si bien González Esteva ha afirmado que en su obra el lector encontrará solo a Cuba, sus poemas filtran indicios que delatan cuán frágil es la Cuba en ellos evocada.

A González Esteva usualmente se le agrupa con la primera generación de escritores exiliados -Hilda Perera, Luis Ricardo Alonso, Celedonio González, Matías Montes Huidobro (Espinosa Domínguez 160-165; Rojas 417); sin embargo, el acoplamiento en sus poemas de los motivos de inminencia y extrañeza, de memoria y novedad, lo acerca a los escritores "cubanoamericanos" (cuya "americanidad", dicho sea de paso, a veces consiste principalmente en el uso de la lengua inglesa). Entre ellos, uno de los más destacados, aunque menos estudiados, es Ricardo Pau-Llosa, quien nació en La Habana y llegó al exilio en 1960. Además de poeta, Pau-Llosa es un reconocido coleccionista y crítico de arte, en particular de pintura y escultura hispanoamericana. Al igual que González Esteva, reside en Miami.

Todavía adolescente, Pau-Llosa se inicia como poeta con Veinticinco poemas (1973), un librito en español que dejará pocos rastros en su obra posterior. Diez años más tarde publica su segundo poemario, ahora en inglés, Sorting Metaphors (1983), al que han seguido Bread of the Imagined (1991), Cuba (1993), Vereda Tropical (1999), The Mastery Impulse (2003) y Parable Hunter (2008). Poco amigo de hacer concesiones al lector, Pau-Llosa escribe una poesía que no evita la dificultad o la abstracción, proclividad que le ha ganado el mote de "Miami's irascible ambassador to the world of ideas" (Mastrapa 37). Como ha aclarado en varias entrevistas, para él un poema es un acto de conocimiento modelado en la reducción fenomenológica (Milián 145-147; Dick 12-13). En la traslación a la poesía del epoché, la metáfora es el recurso fundamental, pues le permite al poeta desnudar el objeto de lo accesorio para captar sus cualidades esenciales (de ahí el título "Sorting Metaphors"). Por ello, los poemas de Pau-Llosa se desenvuelven

\footnotetext{
Revista Iberoamericana, Vol. LXXIX, Núm. 243, Abril-Junio 2013, 337-347 ISSN 0034-9631 (Impreso) ISSN 2154-4794 (Electrónico)
} 
como aventuras cognoscitivas, esfuerzos por descubrir, si no el nombre exacto de la cosa, al menos su imagen fiel. Algunos de ellos, prescindiendo de la sintaxis, se configuran como una retahíla de imágenes relacionadas por la semántica. Así el poema titulado "Ladder", donde Pau-Llosa se propone definir la "escaleridad". El escalonamiento de metáforas evoca la escala platónica del saber, con la diferencia de que, a medida que el lector recorre el poema, va bajando de verso en verso, de peldaño en peldaño, hasta alcanzar, no el mundo de los arquetipos, sino "la cálida tierra":

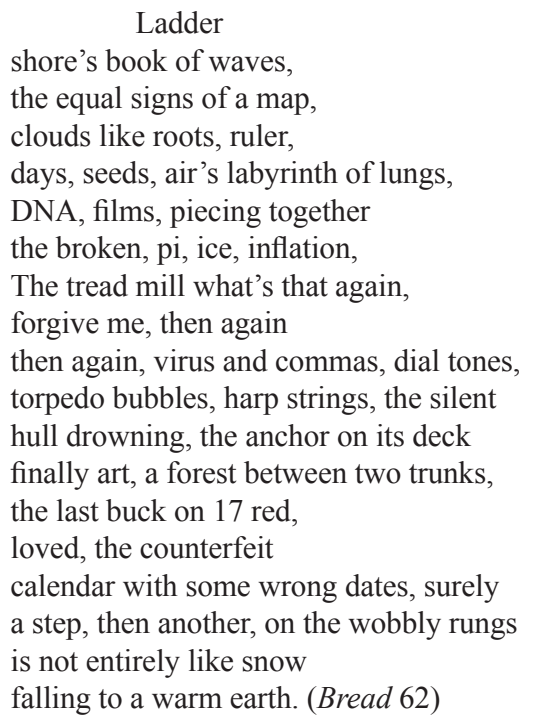

Aunque toda la poesía de Pau-Llosa se rige por este deseo de dominio cognoscitivo, el "mastery impulse" que nombra en otro de sus poemarios, el objeto privilegiado de ese deseo es Cuba. Su poemario más conocido lleva por único título el nombre de la isla, como si el libro, igual que la noche de González Esteva, fuese todo Cuba. En los poemas de la primera parte, "Mapa de Cuba", Pau-Llosa recrea la topografía de la isla y algunos de sus parajes y paisajes más célebres: "Valle de Viñales", "Minas de Cobre", "Tabaco de Vuelta Abajo", "Salto de la Hanabanilla", "Sierra Maestra", "Dos Ríos", "Baracoa", "Cuevas de Bellamar". Mas no se trata de una poesía nativista al estilo del siboneyismo del siglo XIX, o siquiera de sus avatares posteriores como Trópico (1930) de Eugenio Florit y Aventura con los aguinaldos (1947) de Samuel Feijóo. Puesto que Pau-Llosa no ha visto en persona las escenas que describe, los poemas abundan en referencias a fotografías, mapas, anuncios, refranes y recuerdos vicarios: el archivo que da al poeta acceso a la isla; la historia de "Cuba" (el poemario más que el país). En "Return to 
Havana", un texto clave de la última sección del libro, "At Home in Exile", Pau-Llosa reconoce la paradoja de sentir nostalgia por un lugar que apenas llegó a conocer, "a strange locale, missed without possession" (89). Y sin embargo, no por ello renuncia a la pertenencia a la isla, afirmada una y otra vez mediante la evocación de Cuba, fuera de Cuba, como si estuviera en Cuba.

Titulado precisamente "Exile", uno de los poemas de Bread of the Imagined, el poemario que precede (y anticipa) Cuba, Pau-Llosa dilucida la poética que sostiene su saber de ausencia. El epígrafe es el último verso de "Una oscura pradera me convida" de José Lezama Lima: "Un pájaro y otro ya no tiemblan", Aunque el propio Lezama ha dicho que su poema es una evocación de la muerte, del no ser (Poesía 86), también puede leerse como una reflexión sobre el acto de creación; la oscura pradera representa la experiencia estética, el lugar de la poesía, a cuyo "centro henchido" el poeta, despacioso, penetra. Pau-Llosa extiende esta segunda lectura: el poema de Lezama narra además la fantasía de desexilio, el nostos de la nostalgia. En "Exile" el pájaro y su otro se corresponden con los pájaros que el hablante contempla desde el exilio y los pájaros de su "otra juventud", su niñez habanera. Los pájaros del presente, grises y silenciosos, vuelan desprovistos de significación; su trayectoria circular es cifra de esterilidad, quizás como la vida del desterrado. En cambio, los pájaros de la juventud están cargados de sentido:

Exile

"Un pájaro y otro ya no tiemblan."

-Lezama Lima

Let these birds turn into circles,

holding themselves like so much gray, and let them mean nothing

else than the knot of trajectories.

In the parks of another youth

those other birds trembled branches

into lines that broke the sky,

and from the breeze-drawn shadows

they sang as clouds of leaves

quivered like minnows.

Each bird was a heart in the great green heart of the tree.

In those parks we would have melted

into the one song of a thousand

brown, dwarfed birds together

composing their gigantic call,

the harmony that guides and loves.

Sevista Iberoamericana, Vol. LXxix, Núm. 243, Abril-Junio 2013, 337-347 
Then we would have made the hours pure with the hand, the kiss, the word. (26)

El primer verso -"Let those birds turn into circles"- encarna el fiat creador que le permite al hablante asumir el papel de lo que Lezama, en La expresión americana (1957), denomina "sujeto metafórico", o sea, el sujeto que genera metáforas (10). La transformación de los pájaros en círculos anticipa el otro acto de creación, o más bien, de recreación: la de los pájaros y parques de su niñez. A diferencia de los pájaros en "Una oscura pradera", que dejan de temblar una vez que el éxtasis (de la muerte o la poesis) ha concluido, los de "Exile" no dejan de temblar; es más, imparten su temblor a las ramas. Su gorjeo compone una "gigantic call", llamada tanto como canto, que restaura la armonía rota por el exilio, "the harmony that guides and loves". No debemos pasar por alto el eco en este verso del último de La Divina Comedia: "l'amor che move il sole e l'altre stelle". En efecto, la capacidad de imaginación del poeta lo traslada a un espacio paradisíaco de intimidad y convivencia. Lo que en Lezama es oscura pradera, en el poema de Pau-Llosa es un parque (etimológicamente, un terreno cercado; o sea, una especie de isla -o un nido-) donde se recupera la armonía entre el hablante y su entorno, emblematizada por el trino unitario de los pájaros. Como González Esteva, Pau-Llosa aún los oye.

En el poema que sigue, "Key Biscayne", el poeta se define como "the fisher of metaphors/ that bind the layered water/ to bark and fronds". En vez de pescador de hombres, pescador de metáforas (en inglés, el juego de palabras se aprovecha de la aliteración entre men y metaphors -como si el quehacer poético fuese a la vez un hacer de salvación-). La virtud de las metáforas es ligar, "bind", acción que adquiere suma importancia cuando lo que se liga es presente y pasado, aquí y allá. De este modo la poesía resarce la dispersión del destierro, como fragmentos a su imán. Y en Pau-Llosa como en Lezama, el imán es la imaginación: "the power of the imagination/ to weave past and present" ( $C u b a$ 45). Se trata en el fondo de una poética de la correspondencia, de los missing links, cuyo resultado, como afirma en el último poema de Cuba, es una vida "en deuda con la imaginación":

One can always take up arms or that other critical resistance called exile, if you bring all of yourself into the flight. Then a life more in debt to the imagination can begin. (108)

Pero este pasaje también nos dice que las deudas con la imaginación se pagan. El contexto bélico -"take up arms"- introduce otro juego de palabras: “"into the flight"

Revista Iberoamericana, Vol. LXXIX, Núm. 243,
ISSN 0034-9631 (Impreso) 
o "into the fight”? ¿Es la imaginación fuga o asalto? El equívoco anuncia el monto de la deuda, tanto en la poesía de Pau-Llosa como en la de González Esteva. González Esteva: "Yo no sé como quién soy" (Escrito 47). El saber está reñido con el ser. Si yo no sé como quién soy, ¿qué sabe quién soy? -y ¿quién soy al saber? Pau-Llosa: "I live a kind of dual citizenship - my life style is American, my imagination is Cuban, or old Cuban" (Milián 144). El diario vivir se opone a la imaginación, con el agravante de que el país imaginado ya no existe: "No man/ should have to outlive his nation, as I have" (Parable 19). El intento por superar la discontinuidad del exilio promueve otras discontinuidades, otras fracturas. La imaginación priva, en todos los sentidos. No obstante, para estos dos poetas, como para otros de su generación (entre ellos el autor de este ensayo), el sufrir este tipo de privaciones no es una sentencia sino un destino. El sabio de ausencia sabe que en la ausencia encuentra su mejor presente: la seguridad de recibir lo que no se espera.

\section{OBRAS CITADAS}

Asiaín, Aurelio. "Jardín estricto: Entrevista de Orlando González Esteva con Aurelio Asiaín”. Vuelta 149 (1989): 53-57.

Colón, Cristóbal. Diario de a bordo. Luis Arranz, ed. Madrid: Historia 16, 1985.

Dante Alighieri. La Divina Commedia. S. A. Barbi, ed. Vol. III. Firenze: Sansoni, 1930.

Dick, Bruce Allen. "Tropic of Tropes: A Conversation with Poet \& Art Critic Ricardo Pau-Llosa." The Writer's Chronicle 42/4 (2010): 8-14.

Espinosa Domínguez, Carlos. El peregrino en comarca ajena. Panorama crítico de la literatura cubana del exilio. Boulder: Society of Spanish and Spanish American Studies, 2001.

Feijóo, Samuel. Aventura con los aguinaldos: infancia de la tataguaya. Cuba: s.n., 1947.

Florit, Eugenio. Trópico (1928-1929). La Habana: Revista de Avance, 1930.

García, Cristina. Dreaming in Cuban. Nueva York: Knopf, 1992.

García Tudurí, Mercedes. Ausencia. Madrid: Progreso, 1968. Tiempo de exilio. Nueva York: Senda Nueva de Ediciones, 1983.

Guitart, Jorge. The Empress of Frozen Custard. Buffalo: BlazeVOX, 2009.

González Esteva, Orlando. Casa de todos. Madrid: Editorial Pre-Textos, 2005. Cuerpos en bandeja. Frutas y erotismo en Cuba. México, D.F.: Libros de la Espiral, 1998.

Elogio del garabato. México, D.F.: Editorial Vuelta, 1994. Escrito para borrar. Madrid: Ediciones La Palma, 1997. Fosa común. México, D.F.: Editorial Vuelta, 1996. La noche y los suyos. México, D.F.: Ediciones del Ermitaño, 2005. Mañas de la poesía. Miami: Asoc. de Hispanistas de las Américas, 1981.

Revista Iberoamericana, Vol. LXXIX, Núm. 243, Abril-Junio 2013,
ISSN 0034-9631 (Impreso) 
Mi vida con los delfines. México, D.F.: Trilce, 1998.

El pájaro tras la flecha. México, D.F.: Vuelta, 1988.

¿Qué edad cumple la luz esta mañana? México, D.F.: Fondo de Cultura Económica, 2008.

Tallar en nubes. Mexico, D.F.: Editorial Aldus, 1999.

Hass, Robert, ed. y trad. The Essential Haiku. Versions of Bashō, Buson, and Issa. Hopewell: Ecco Press, 1994.

LaCapra, Dominick. Writing History, Writing Trauma. Baltimore: Johns Hopkins UP, 2001.

Lezama Lima, José. La expresión americana y otros ensayos. Montevideo: Editorial Arca, 1969.

Poesía. Emilio de Armas, ed. Madrid: Cátedra, 2000.

Mañach, Jorge. Historia y estilo. La Habana: Editorial Minerva, 1944.

Mastrapa, Armando F. "Ricardo Pau-Llosa, Miami's Poet-Whether He Likes it or Not." Saw Palm (2009): 36-50.

Milián, Alberto. "Defying Time and History: An Interview with Ricardo Pau-Llosa." Manoa: A Pacific Journal of International Writing 15.1 (2003): 141-151.

Pau-Llosa, Ricardo. Bread of the Imagined. Tempe: Bilingual Press, 1992. Cuba. Pittsburgh: Carnegie Mellon UP, 1993.

The Mastery Impulse. Pittsburgh: Carnegie Mellon UP, 2003.

Parable Hunter. Pittsburgh: Carnegie Mellon UP, 2008.

Sorting Metaphors. Tallahassee, FL: Anhinga Press, 1983.

Veinticinco poemas. Miami: Universal, 1973.

Vereda tropical. Pittsburgh: Carnegie Mellon UP 1999.

Pérez Firmat, Gustavo. Vidas en vilo. La cultura cubanoamericana. Madrid: Colibrí, 2000.

Rojas, Rafael. Tumbas sin sosiego. Revolución, disidenciayexilio del intelectual cubano. Barcelona: Anagrama, 2006.

Ueda, Makoto, ed. Bashō and His Interpreters: Selected Hokku with Commentary. Stanford: Stanford UP, 1991.

$\begin{array}{llllll}\text { Revista Iberoamericana, Vol. LXXIX, Núm. 243, } & \text { Abril-Junio 2013, } & \text { 337-347 } \\ \text { ISSN 0034-9631 (Impreso) }\end{array}$ 
